\title{
DR. H. HADEN
}

Dr. H. Haden, joint Head of the Physical Medicine Department of the Johannesburg General Hospital and the Sub-departments of Physiotherapy and Occupational Therapy Witwatersrand University, died following a major operation on July 17th, 1956, at the age of 52 . He leaves a widow and one son.

Dr. Haden joined the staff of the University as a lecturer in 1940 and subsequently became Departmental head. He always strove to maintain the highest standard of education and a responsibility to the sick, and due to the fact that never in his service to the University would he accept second best, there are now many graduates in Physiotherapy who enjoy the benefits of the scope of training of which they can be justly proud.

In 1946 he pioneered and established a Rehabilitation Centre for the Witwatersrand Native Labour Association in Johannesburg which today is one of the most progressive and successful units of its kind in this Country.

In 1951 he became Conisultant Physical Medicine Specialist to the Johannesburg Fever Hospital, where much in the way of treatment and valuable advance has been made for the early acute Poliomyelitis patients.

Dr. Haden was among the first Physical Medicine Specialists to practice in South Africa and until the time of his death, had one of the foremost private practices in Johannesburg, which was established in 1936.

Outside his professional life he was a great sportsman, his main interests being rugby and tennis, and in his latter years he was coach to the under nineteen's rugby teams of the University.

As a sportsman, doctor and friend, Dr. Haden will be sadly missed and his passing a loss to Physiotherapy as a whole.

\section{A TRIBUTE}

Dr. H. Haden in his professional work had many interests. We would, however, not do justice to him or his achievement, if we tried to ascertain which of his many activities was nearest his heart. He strove for perfection in every field.

Perhaps a special word may be said in connection with Dr. Haden's interest in the advancement of Rehabilitation. All those who worked with and under him in this field will hold him in high regard as one of the pioneers in this comparatively young venture in South Africa. For this field he was particularly suited through his gift to encourage and appreciate the co-operation of his co-workers, to induce loyalty, and so to produce that most essential prerequisite: team-work.

After years of fundamental work, known only to a small group of his associates, it was the Medical Congress in Johannesburg in 1953, which provided a forum for him to show what efforts were being made especially in the rehabilitation of spinal paraplegics. The address and demonstration were acclaimed by all present as proof of a remarkable step forward.

Returning from a most stimulating study-tour to England, the Continent, and the United States, Dr. Haden brought to this country new ideas, especially in the field of the treatment of polio-sufferers.

He imparted his enthusiasm to the medical profession, to us physiotherapists, and to all those engaged in the field of rehabilitation. He gave a tremendous impetus to the rehabilitative effort in this country and helped to a fuller understanding of the possibilities of rehabilitation.

He has left us much too soon, with much of the work to which he was devoted still undone. But he has left behind co-workers who will always remember the standard at which he aimed, and who, in in this spirit, will try to fulfil his high ambitions, for the benefit of the suffering. 